\title{
Digital transformation in regional transportation and social infrastructure
}

\author{
Elena Naumova ${ }^{1}$, Vasilii Buniak², Galina Golubnichaya², Lidiia Volkova $^{2}$, and Viktoria \\ Vilken ${ }^{3, *}$ \\ ${ }^{1}$ Saint Petersburg State Maritime Technical University, 190121, Lotsmanskaya Ulitsa, 10, St. \\ Petersburg, Russian Federation \\ ${ }^{2}$ Financial University under the Government of the Russian Federation (Moscow) St. Petersburg \\ branch, 197198, Syezhinskaya Str., 15-17, St. Petersburg, Russian Federation \\ ${ }^{3}$ Peter the Great St. Petersburg Polytechnic University, 195251, Polytechnicheskaya, 29, St. \\ Petersburg, Russian Federation
}

\begin{abstract}
The article is devoted to the research of the strategy of implementing regional digitalization projects regarding the transportation and social infrastructure. The purpose of the study is to identify the problems of regional digitalization projects and develop a methodology for the formation of a regional digitalization program. The study formed the key aspects of the formation of regional digitalization programs in modern conditions. The scope of the possible application of digital technologies is expanding due to the branches of the regional economy. The authors consider the use of public-private partnership instruments, attracting sources of project financing and venture financing. Three strategies for implementing the digitalization of the regional economy with the relevant level of risks and costs are studied. According to the authors' approach the simulation strategy of the region's digital transformation is shown as the most conservative of the three. The defensive strategy for digital transformation of the region involves the integrated use of digital technology transfer allowing to achieve much greater efficiency. It is proved that the offensive strategy consists in the active financing of regional projects with the creating regional technological reserves and technological competencies resulting in the maximum level of costs and risk.
\end{abstract}

\section{Introduction}

Digitalization of the economy changes the structure of the national economy used by economic entities in business models implementation, in business processes carried out by enterprises and algorithms of cooperation between businesses, state and society [1-3]. S. Adams in his work is considering the issues of business digital transformation and its impact on the national economy [4]. C. Millar is exploring digitalization objectives on the level of an enterprise, a country and the world in general [5]. C. Matt is exploring the advantages of economy's digital transformation resulting from changes in business processes and algorithms of enterprise functioning [6]. The concept of the digital economy should be

\footnotetext{
* Corresponding author: sbe@ list.ru
} 
differed from the technological revolution due to the nature of the digital revolution being not a technological revolution, but a social revolution comparable in importance to the Neolithic, Class and Industrial revolutions [7]. Undoubtedly the digital revolution results in the formation of a new economic system, which can be called the network economy. In this regard, today it is necessary to understand the essence of the changes arising as a result of digitalization and to predict further impacts of these changes on the national socio-economic development. Today, the digital economy development project in the Russian Federation is performed in accordance with the Decree of the President of the Russian Federation dated May 7, 2018 «On National Goals and Strategic Objectives of Development of the Russian Federation up to 2024» as well as the national program «Digital Economy of the Russian Federation».

Three key objectives to implement the national program «Digital Economy» were declared. Objective one is to increase internal spending on national economy's digital transformation at least three-fold compared to 2017. Objective two is to create a stable, reliable and safe in regard to cyber threats big data infrastructure (data transmission, processing and storage) on the territory of the Russian Federation, which will be available for all individuals and legal entities. Objective three is the transition of state authorities, regional authorities, local governments and commercial organizations to national software.

Today, following the national programs adopted at the national level, regional projects in economy's digitalization have been forming and implementing. The researchers show a growing interest to the problems of national and regional digitalization.

Researchers in Russia consider the problems like the essence of economy's digitalization and its impact on the socio-economic development of the country [8], algorithms of regional digitalization [9-10], methodology of digitalization of the national and regional economy [1112].

Bublik N.D., Lukina I.I., Chuvilin D.V., Shafikov T.A., Yunusova R.F. are exploring the ways of regional economy's digital transformation in the context of implementation of the national program «Digital Economy of the Russian Federation» [13]. Yershova T.V., Khokhlov Yu.E., Shaposhnik S.B. are considering the problem of assessing the level of digital economy's development in different regions of the Russian Federation [14-15]. Ivanov V.V. and Malinetsky G.G. are considering the consequences of introduction of information and communication technologies into various sectors of economy [16]. Revenko N.S. is trying to understand the possible effects of digital transformation of national economy taking into account the experience of digital economy's development in the United States [17]. Prokhorov A. and Konik L. are considering the risks of national economy's digital transformation in modern environment, taking into account the experience of different countries [18]. One should mention that despite the increased interest of researchers to the problem of economy's digitalization at the state and global levels, the issues of regional digitalization receive much less attention.

\section{Materials and methods}

The digitalization of economy in a narrow sense is the transition of economic entities and organizations from the use of data in analog format to the use of data in digital format. However, modern researchers interpret the process of digitalization in a broader sense. For example, K. Schwab considers the digitalization of economy as a large-scale transition to a new technological order using the achievements of the fourth industrial revolution [1]. Yershova T.V. and Khokhlov Yu.E. understand digital economy as the transformation of macroeconomic mechanism under the influence of mass introduction of information and communication technologies into the major part of economic sectors [15]. F. Pinzaru understands digital economy as an economic structure based on the effective acquisition of 
information in digital format, the distribution and systematization of information and the use of information in economic interaction [19].

One of the key directions of digitalization implemented within the framework of industrial production is called "The Factory of the Future". The Factory of the Future represents a vision of transformation of industrial production in the conditions of economy's digitalization. In the context of development of The Factory of the Future, business processes of industrial enterprises are changing as follows:

- transformation of production structure of an industrial enterprise by means of flexible arrangement of modular production lines instead of fixed conveyor lines;

- production process automatic control in the conditions, when the production equipment is synchronized with the information system of the enterprise;

- digitization of all processes included in the life cycle of the products production.

Flexible production is a way of efficient transformation of production processes in accordance with the digitalization requirements. This method of transformation of industrial production is based on the concept of "Industry 4.0" and implies the possibility of an industrial enterprise to rapidly switch to production of new types of products. Flexible production is based on the active use of data, within which data generation, collection, analysis and interpretation as well as production process management are carried out through the interaction of a person with the production equipment.

Key features of a flexible production in the conditions of digitalization are as follows:

- the possibility to produce different products on the same equipment or the same products on different types of equipment;

- well-thought possibility to transform the production equipment taking into account the requirements for the production of individual products;

- the ability to produce unique products and customized products in industrial conditions.

Another important area of digitalization is the development of digital models and platforms.

Digital platform is a set of technologies that provide the formation of a system of effective digital interaction of value chain participants in any industry.

In the conditions of development of the digital platform a digital business model is formed, which through the use of modern technologies ensures effective interaction between economic entities based on the principles of mass interactions and maximally expedited transactions. Thus, within the framework of the digital business model a system of multidimensional algorithmized and mutually beneficial schemes of relationships arising between heterogeneous though independent participants of any economic sector forms. The digital business model operates in a single information space, within which transaction costs are significantly reduced.

Modern concepts of national economy's digitalization are criticized as well by researchers. In particular, Professor Veduta E.N. believes that the widespread introduction of the "data economy" does not contribute to finding a solution to global macroeconomic problems. In his opinion, the world economy is experiencing a global crisis, which is primarily due to the disproportionate economic development, that is, the gap between the level of development of some sectors of the world and national economies and the needs of states, exporters and households [20]. In these conditions, globalization ideologists introduce certain elements of digital technologies, however, they do it spontaneously, without any scientifically based economic and mathematical model, with the help of which digital economy will make it possible to truly improve the efficiency of management decisions to overcome global macroeconomic problems.

According to E.N. Veduta, digital economy at the national and global level should be organized as an economic cybersystem that will simulate the mechanism of harmonization of internal economic scheduled "input-output" calculations at the macro-, meso- and micro- 
levels. This will make it possible to overcome disproportions in sectoral development. Thus, the balance can be achieved in the context of effective distribution of "social resource of labor according to social needs". E.N. Veduta proposes to create a working group of specialists of various profiles to solve methodological, program and organizational and technical problems as an algorithm for introduction of digital economy in the format of economic cybersystem.

S. Nikolaev sees a number of systemic shortcomings in the national approach to implementation of economy's digitalization. First of all, he points to the absence of a conceptual level of management in the normative program documents on digital economy's development in Russia. In his opinion, economy's digitalization includes the formation of a new social and economic model defined at the conceptual level. Thus, S. Nikolaev points to the absence in domestic program documents on economy's digitalization of a meta-systemic approach focused on the ultra long-term forecast of social and economic development. In addition, S. Nikolaev believes that inefficient domestic system of economic management does not represent a sufficient basis for implementation of economy's digitalization. In addition to the shortcomings of strategic planning of digital transformation of the economy, the problem is exacerbated by the inefficiency of the state as an executive body of the decisions taken. According to S. Nikolaev, to successfully implement the project of domestic economy's digitalization the following two fundamental measures are necessary: first, the development of a new concept of social and economic development, based on the current civilizational trends; second, optimization of the activities of the state as the developer and implementer of strategic initiatives. There could be discussion regarding this point of view due to the specific issues being considered by other scientists.

Speaking about regional economy's digitalization, first of all it is necessary to assess the current level of development of the digital economy in different regions of the country. Skolkovo Center has developed the methodology, which helped to assess and calculate the index of "Digital Russia" project for all 85 subjects of the Russian Federation. Figure 1 illustrates the dynamics of the index "Digital Russia" in 2017-2018 in the context of federal districts.

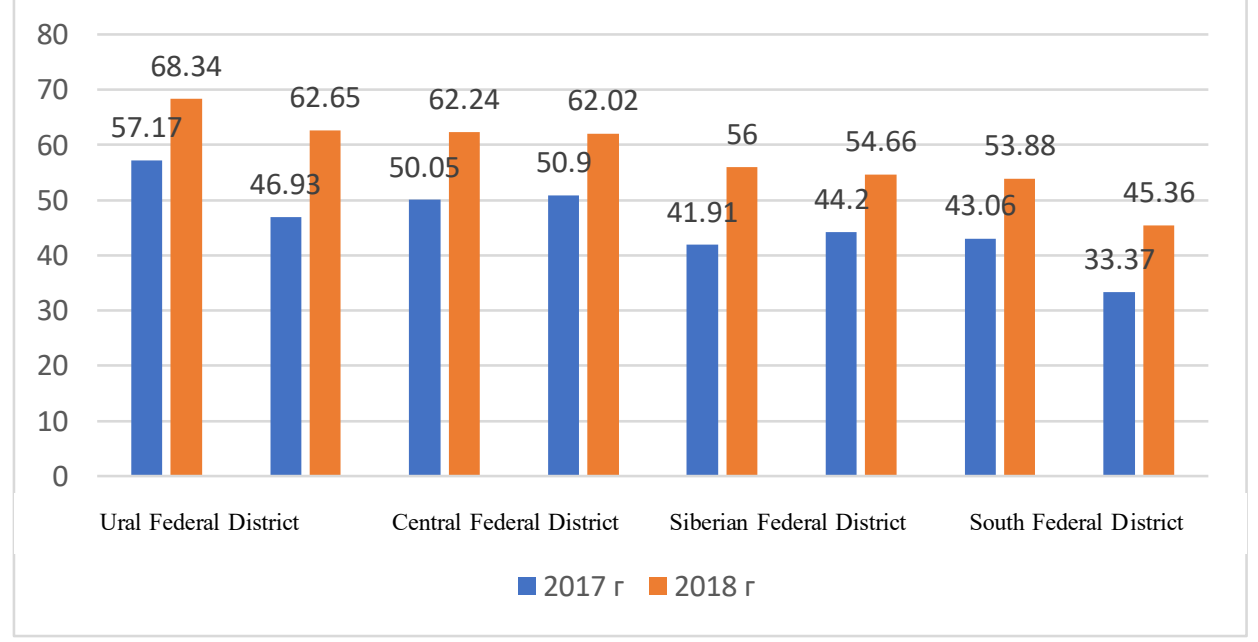

Fig. 1. The level of digital economy development in federal districts of the Russian Federation.

Both in 2017 and 2018, the maximum level of digital economy's development is registered in the Ural Federal District. At the same time, Digital Economy Development Index in the Ural Federal District went up from 57.17 to 68.34. The North-West Federal District in 2017 took the second place in terms of digital economy's development, and in 2018 was moved to 
the fourth place. Digital Economy Development Index in the North-West Federal District increased from 50.90 to 62.02 . The other leaders of digital economy's development in 2018 are the Volga Federal District (the Index was 62.65) and the Central Federal District (Digital Economy Development Index was 62.24). One should mention that the capital federal districts like the Central and North-West Federal Districts are not taking the leading positions in the digital economy's development. The minimum level of digitalization is registered at the South Federal District and North Caucasus Federal District. Digital Economy Development Index in the South Federal District increased from 43.06 to 53.88; the Digital Economy Development Index in the North Caucasus Federal District increased from 33.37 to 45.36; however, these levels remain the lowest among the other federal districts.

Figure 2 shows Digital Economy Development Index in dynamics in ten subjects of the Russian Federation showing the leading positions in the level of digitalization.

Moscow reasonably occupies the first place among the subjects of the Russian Federation in terms of the level of digital economy's development - various digitalization programs have been actively implemented in the capital since 2012. The other leading subjects in terms of digitalization include the Republic of Tatarstan, the Republic of Bashkortostan, the city of Saint Petersburg, the city of Moscow, the Leningrad, Tyumen and Novosibirsk regions, KhMAD - Yugra and Yamalo-Nenets Autonomous District.

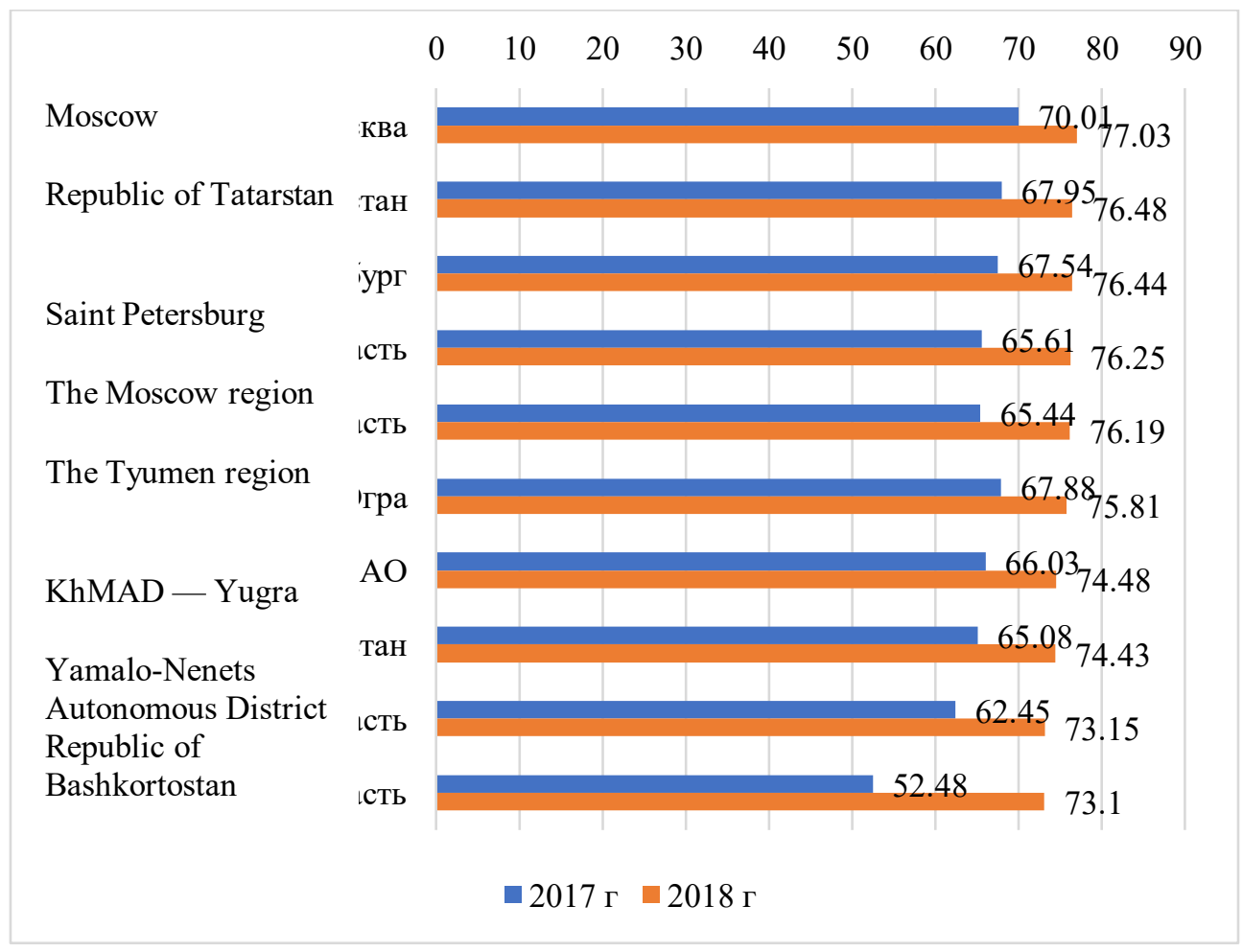

Fig. 2. Subjects of the Russian Federation, showing the leading positions in the level of digital economy's development.

The presence of federal cities like Moscow and Saint Petersburg as well as the Moscow and Leningrad regions among the leaders of digitalization process is expected and justified by the level of socio-economic development and investment attractiveness. At the same time, the other three leaders of digital economy's development should be mentioned. They are 
located in the Arctic zone: the Tyumen region, Yamalo-Nenets Autonomous Region and KhMAD - Yugra. The Novosibirsk region has demonstrated the highest growth among the leading regions in the digital economy's development: the digitalization Index of the region increased from 52.48 to 73.10 . 2018 showed a decreasing gap between the maximum and minimum levels of digital economy's development. This indicates the beginning reduction of interregional digital inequality in Russia.

\section{Results of the research}

\subsection{General trends of digital transformation of regional infrastructure.}

There are general trends in regional digital initiatives implementation under three main directions.

1. Regional digital transport and housing. Various regions and, in particular, the Tyumen and Novgorod regions, the Republic of Northern Ossetia are developing regional projects aimed at introduction of new technologies in the system of housing and communal as well as transportation services. Tyumen Industrial University (TIU) within the framework of the project "Smart City" is engaged in improvement of the city system of informing passengers about bus schedules, implements adaptive traffic lights able to differentiate their work in accordance with the current road situation, and implements the technology of creating intelligent lighting systems. In autumn 2018 North Ossetia launched the projects in transportation and housing and communal services in a pilot mode in the Mozdok district; later the projects will start to operate throughout North Ossetia. One project suggests the creation of an intellectual platform in the sector of housing and communal services, which will allow to maintain a transparent accounting of fares calculated for the used resources. North Ossetians will be able to track public transport movements via their smartphones and check the time of transport arrival at the desired stop.

2. Regional e-budget, agriculture and tourism. The government of the Ryazan region is developing a draft electronic budget. One of the major projects in this direction is a scientific and technological IT-center, which will take under its umbrella all the Ryazan leading ITdevelopers and programmers. The agricultural Altai Territory uses technologies in agriculture to monitor the condition of crop lands from satellites. The system contains information about more than 135 thousand sites, of which $75 \%$ are updated by user and planned culture. Satellites also track the progress of field works as well. According to preliminary estimates, implementation of such technologies will reduce the cost of production processes by $17 \%$. The Kaluga region is implementing a pilot project to create a national data management system, which will eventually provide up-to-date data for all participants of digital transformation, including on a reimbursable basis. The Novgorod region uses new technologies to calculate the number of tourists in the region, receiving information from mobile phones that tourists bring with them (digital trail of tourists' mobile phones are processed).

3. Educational programs in digital economy. The Samara region is planning to have an inflow of IT specialists into the economy of the region in the amount of almost 6 thousand people per year. The Don State Technical University (DSTU) in the South Federal District specializes in digital technologies. This academic year it launches two new master's degree programs: "Intelligent Systems Based on Blockchain Technologies" and "Digital Accounting and Management". Far Eastern Federal University (FEFU) this year launches a master's degree program in cybersecurity law. Its graduates will be able to provide legal support to companies that develop, implement and use the state-of-the-art technologies of artificial intelligence, virtual and augmented reality (VR/AR), blockchain, as well as to calculate legal 
risks when creating startups based on these technologies. Ural Federal University (UrFU) provides basic training of bachelor's degree specialists in the area of information technology, and master's degree specialists in niche specialization. The UrFU training programs are aimed at providing more specialized and deep competencies, including big data analysis, digital modeling of physical systems, geoinformation systems design, artificial intelligence and other relevant specializations.

The following terms of implementation of the national program "Digital Economy" are established: from October 01, 2018 to December 31, 2024. The national program "Digital Economy" includes six federal projects (Figure 3).

It is clear that regional digitalization projects are being implemented in the context of higher and lower programs and activities of strategic development of the Russian Federation. Therefore, it is important to ensure effective integration of the goals of the national program "Digital Economy" and its constituent federal projects with the goals of state development, as well as with the goals of regional digitalization projects.

Analysis of the relationship between the objectives and basic directions of the program "Digital Economy of the Russian Federation" showed that this program is currently primarily focused on the development of key institutions within the framework of which the conditions for effective development of the Russian digital economy will form (such institutions include regulatory management of digital environment, training of personnel for the digital economy through educational system, formation of modern technological competencies through digital projects, digitized public administration), as well as on the development of basic infrastructure elements of national digital economy (these include the domestic information infrastructure, as well as information security).

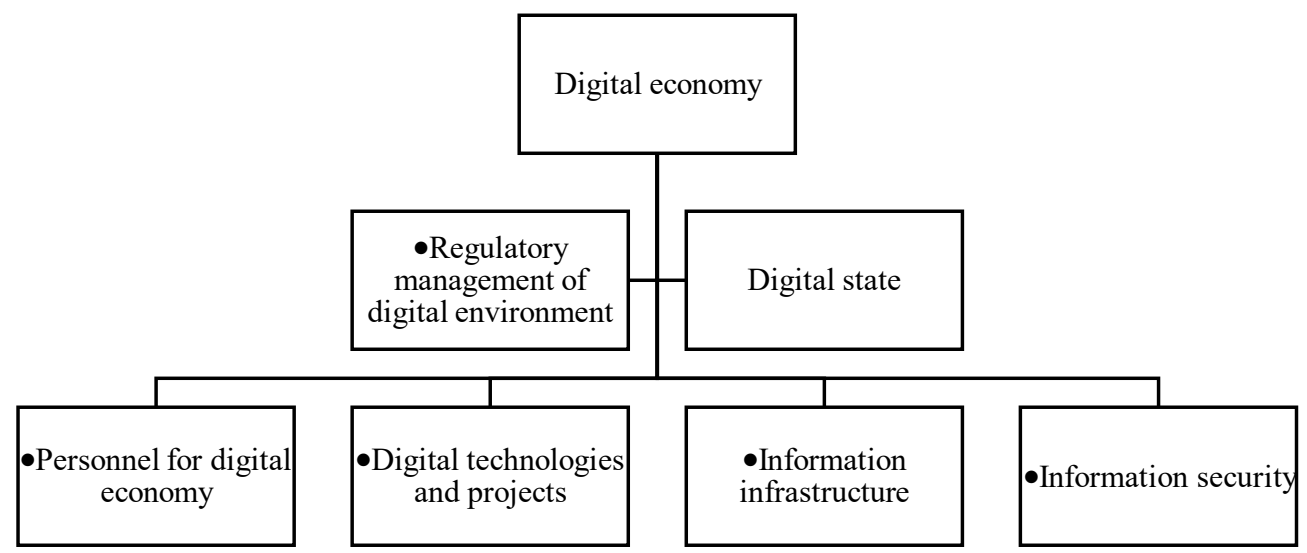

Fig. 3. The Structure of the National Program "Digital Economy". Source: developed by the author.

Figure 4 illustrates the strategic outline of the national program "Digital Economy". At the same time, the national program does not include the issues of implementation of the set tasks both at the regional level and at the level of individual industries. Accordingly, the problem of designing regional economy's digitalization process within the framework of the national program "Digital Economy of the Russian Federation" is still open to finding a solution. 


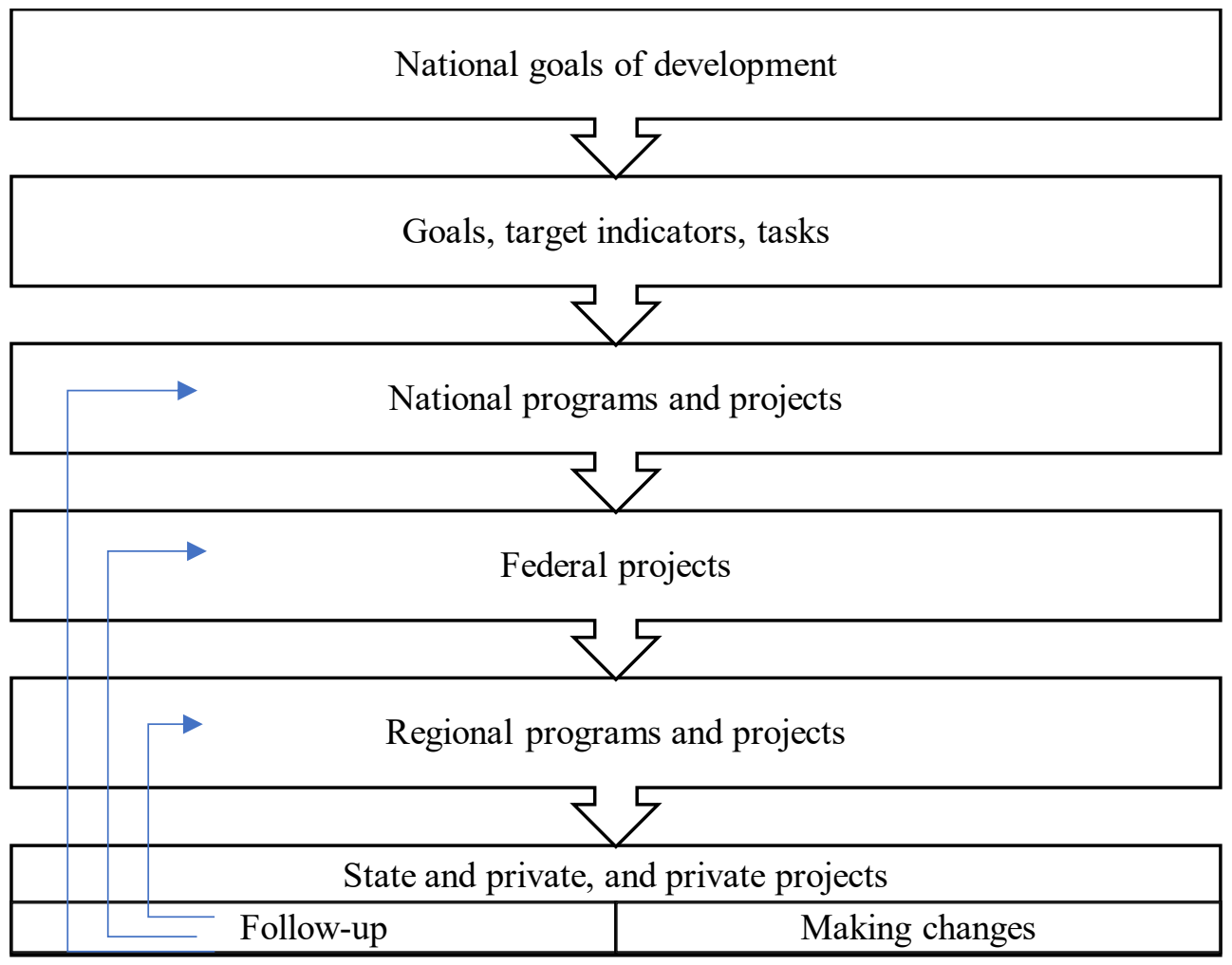

Fig. 4. The Strategic Outline of the National Program "Digital Economy".

Until 2018, only some regions have managed to develop and implement their own digitalization programs. According to the research of the Association of Innovative Regions of Russia (AIRR), at the beginning of 2018, only eight Russian regions had developed their concepts of digitalization. However, at the beginning of implementation process of the national program "Digital Economy of the Russian Federation", all Russian regions were instructed to develop their own programs for development of their regional digital economy in the shortest possible time. At the same time, the process of designing regional programs of digital development is lacking a sufficient methodological and methodical support. Today, all Russian regions have developed and presented their digital economy development programs.

Based on the results of analysis of the programs developed by the Russian regions, the most systematic approach presented in regard to development of regional programs is the approach based on the DECA (Digital Economy Country Assessment) methodology. This methodology was developed by the World Bank and involves assessing countries' readiness for the digital economy. This approach is based on a multidimensional assessment of regional economy in such aspects as the foundation of economy's digitalization, objects of regional economy's digitalization and digital dividends.

The foundation of economy's digitalization under this approach is a set of non-digital foundations of regional economy (regional legislation, state policy applied in the region, the level of R\&D and innovation development, the region's institutional environment, etc.), as well as digital foundations (development of digital infrastructure, ICT penetration level) and digital sector of regional economy represented by information and communication companies operating in the region. Objects of regional economy's digitalization under this approach represent entrepreneurial activity, public administration and population's activity in 
the region. Digital dividends under this approach represent the impact of digitalization on regional economic growth indexes, the level of employment in the region, the quality of services provided and the quality of life of the population.

The approach to digital economy's development in the region based on DECA methodology has been applied by the Novosibirsk region in its digital economy development program. Various sectors of regional economy and social sector are considered as objects of regional economy's digitalization in the said program. These include public administration, regional health, transport and logistics services, "Smart City" system, regional industry, etc.

Figure 5 illustrates the process of regional economy's digital transformation.

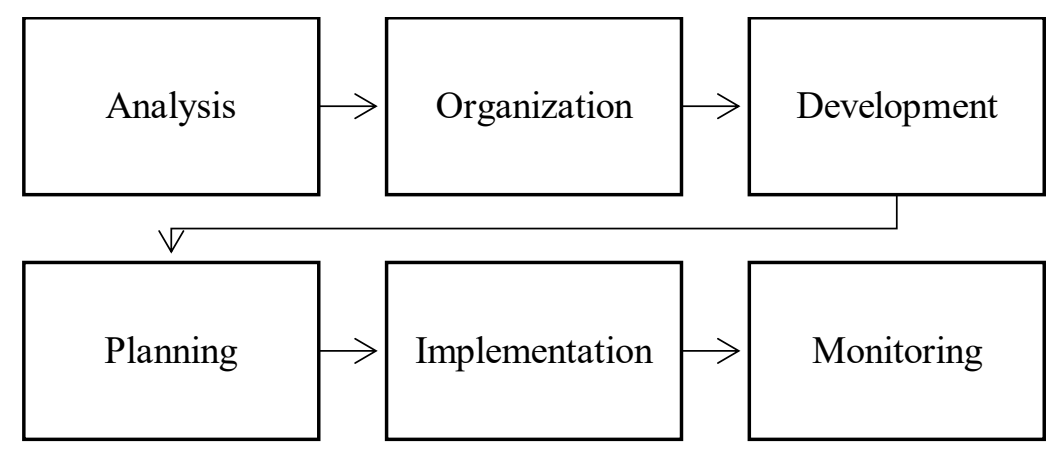

Fig. 5. The Process of Regional Economy's Digital Transformation. Source: developed by the author.

Let's consider the stated stages of the process of regional economy's digital transformation. At the same time, within the framework of the digitalization program, the region forms its own list of priorities to implement digital transformation, taking into account regional priorities of socio-economic development as well as regional competitive advantages. The analysis phase includes SWOT analysis of the regional economy and analysis of existing strategic documents on socio-economic development at the regional level. The region defines the priority directions of digitalization at this stage.

The organizational stage is when partnerships between stakeholders start to form, and the management structure for the regional digitalization process starts to develop. The stage of development is when strategic vision of the results of digital transformation of the region is being developed and formalized. The planning stage includes development of a set of strategic plans for digital transformation: at the regional level, at the sectoral level, at the municipal level. After that the regions develop programs and "road maps" for implementation of the developed strategic plans into the regional and municipal economy.

The implementation stage is when the developed programs start its direct implementation in accordance with the "road maps". The monitoring stage is devoted to comparing the planned results of regional economy's digitalization with the actual ones and evaluating the efficiency of the implemented strategic plans.

The following advantages can be underlined in the development of DECA-based regional digitalization projects and programs. First, the region's digitalization management is carried out on the basis of multi-stage analysis and assessment of the situation in the region. Second, this approach structures the process of regional digitalization. Third, within the framework of this approach the conceptual scheme of the region's digitalization process is formed. But there is also a significant disadvantage of the approach: its application focuses more on the assessment of the situation in the region than on the management of the region's development in the context of digitalization. Thus, the analysis of publicly accessible regional programs of digitalization showed that the lack of methodological support to implementation of regional programs of digitalization development is still present. It is necessary to ensure the transition of regional digitalization projects from the expert-heuristic approach to the 
quantitative justification of the processes of selecting target orientations, tools, resources and activities for the implementation of digital transformation of regions. At the same time, for quantitative justification of various aspects of regional digitalization projects it is advisable to use criteria of achieved socio-economic efficiency of projects and risk levels.

As part of the proposed approach to the formation of regional digitalization projects, a number of scientific and practical tasks should be solved during the process of regional digitalization project development.

First, it is necessary to assess the level of use of modern digital technologies in the areas like public administration, social sphere and economy in the region.

Second, it is necessary to form a methodological apparatus that will allow to effectively plan the goals of regional digitalization and objectively assess the results of digitalization activities.

Third, it is necessary to form a list of possible options for digitalization of the region and to compare them by quantitative analysis; after that, choose the optimal one.

Fourth, it is necessary to form organizational and financial mechanism for the regional project, optimal for the chosen way of digitalization, and to form the resource base of the project.

Fifth, it is necessary to create a risk register for the regional digitalization project, to conduct risk qualitative and quantitative analysis and to develop a set of measures to manage the identified risks.

Finally, it is necessary to create a forecast of the results of regional digitalization project implementation in the context of short-term, medium-term and long-term periods.

While designing the list of options for digitalization of the region it is advisable to analyze the possibilities of application of digital technologies on the scale of the region (Figure 6):

The areas of digital application in the region are differentiated by the achievable application, acceptable application and possible application of digital technologies in the region. Digital technologies achievable application area in the region includes a set of priority branches of the regional economy, with personnel capacity and infrastructural capabilities necessary for accelerated digitalization. Digital technologies acceptable application area in the region is expanding through those branches of the regional economy, which are characterized by regulatory support and sufficient level of security necessary for digitalization in the absence of the said infrastructure and personnel resources.

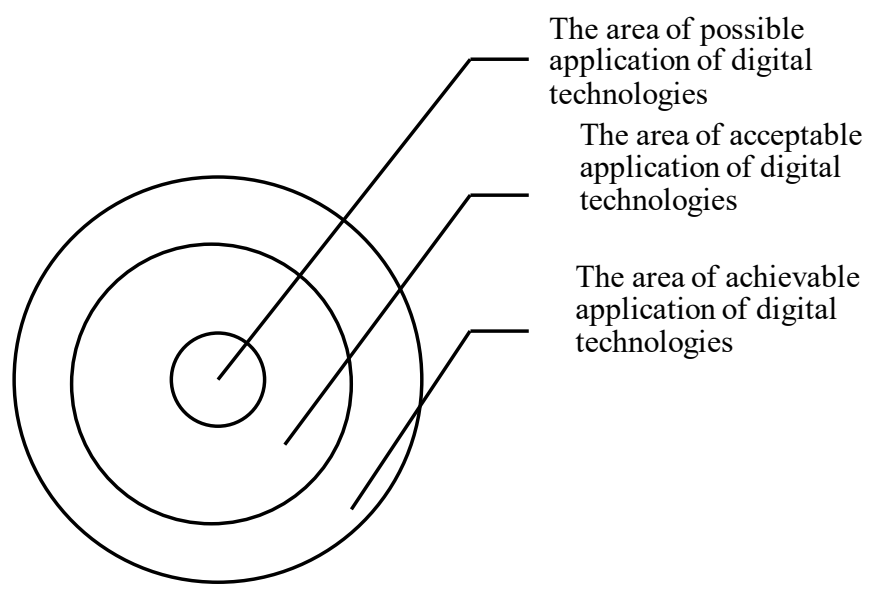

Fig. 6. Areas of application of digital technologies in the socio-economic system of the region.

Source: developed by the author. 
Digital technologies possible application is expanding through the branches of the regional economy with the competencies and technological facilities necessary for digitalization; however, the required legal and regulatory support is lacking and the level of security is currently insufficient to achieve digitalization.

As digital technologies can be applied in multiple areas of regional economy, digitalization strategy can now be defined taking into account the necessary costs for transformation into digital technologies, the level of expected efficiency and risks.

\subsection{Main strategies of digital transformation of regional infrastructure.}

There are three strategies to achieve digitalization of regional economy: simulation, defensive and offensive strategies.

Simulation strategy of digital transformation of the region is the most conservative of the three. It is based on the large-scale introduction of approved algorithms of digital transformation and transfer of various digital technologies through their replication into the regional economy. This digital transformation strategy will require minimum costs and risks from the region. However, the level of expected strategy efficiency is also minimal. To implement the strategy, it is necessary to prepare the infrastructure for technologies replication in the region as well as the necessary number of qualified personnel.

The defensive strategy of digital transformation of the region involves the comprehensive use of digital technologies transfer and own technologies in the format of pilot projects. This strategy provides the opportunity to form industry cases, which can be replicated in other regions. When implementing this strategy, it is necessary to develop regulatory support for pilot technological projects and ensure their safety. The defensive strategy is much more expensive in comparison with the simulation strategy. At the same time, the defensive strategy implementation contributes to increasing the digital competitiveness of the region, thus allowing to achieve significantly greater efficiency.

The offensive strategy of digital transformation in the region implies heavy financial support of regional projects aimed at creation of own technological resources and development of unique technological competences. This strategy is characterized by the maximum costs for its implementation and the highest risks. Accordingly, this necessitates the use of public-private partnership tools, attracting sources of project and venture financial support. This strategy is characterized by the maximum potential of expected efficiency due to the possibility of the region to achieve technological leadership on the territory of the country and even in the international scale.

\section{Discussion}

To assess the possibility to implement one of the stated strategies described above in regional transformation, it is advisable to use the "digital attractiveness" factor.

$$
F d a=\frac{P s d}{C}
$$

Where $F d a$ is the digital attractiveness factor; $P s d$ is the sector digitalization potential; $C$ is costs to digitalization.

In turn, the sector digitalization potential is calculated by the following formula:

$$
P s d=\frac{D e * P e}{C}
$$

Where $D e$ is the effect from digitalization; $P e$ is the probability of reaching the expected effect. 
The costs for digitalization of individual industries consists of the costs to creating a digital infrastructure, provide personnel training, develop a regulatory framework, ensure safety and form the necessary technological competencies. At the same time, the potential for digitalization efficiency is formed by the use of the implemented digital technologies in the industry. This criterion of making managerial decisions makes it possible to carry out quantitative comparison of different sectors of the regional economy and thus choose the priorities of the regional economy digitalization. Estimating individual objects and directions of digitalization of the region by this criterion makes it possible to make a primary choice of digitalization strategy. The objects with the average ratio of costs for digitalization to potential effect are part of defensive strategy. Accordingly, the objects with a low ratio fall within the scope of simulation strategy, while the objects with a high ratio are part of offensive strategy.

\section{Conclusion}

In the context of regional economy digitalization the issue of methodological support to the process of regional digitalization projects development should be noted. Russian regions in the conditions of insufficient methodological and methodical support design their digitalization projects, focusing mainly on their own experience and competencies. However, digital transformation being the process with system-wide implications for all regions of the country requires the use of the most effective approaches to development of digitalization projects on a regional level. At present, the majority of regional digitalization programs use expert-heuristic approach. In the process of developing regional programs of digitalization it is necessary to use quantitative cost and possible effects estimation, and select digitalization priorities and strategies. As part of the proposed approach to the development of regional digitalization projects, the analysis of digital development of the region is considered as well as choosing the optimal strategy for digital transformation for a specific region through quantitative estimations.

\section{References:}

1. K. Schwab. The fourth industrial revolution (New York, Crown Business, 2017).

2. N. Negroponte. Bits and Atoms. Wired magazine. http://web.media.mit.edu/ nicholas/Wired/WIRED3-01.html.

3. L. Anderson, I. Wladawsky-Berger. The 4 Things It Takes to Succeed in the Digital Economy. Harvard business review (2016). https://hbr.org/2016/03/the-4-things-ittakes-to-succeed-in-the-digital-economy

4. S. Adams, C. Clayton. On What He Got Wrong About Disruptive Innovation (2016): https://www.forbes.com/sites/forbestreptalks/2016/10/03/claytonchristensen-on-what-he-got-wrong-about-disruptive-innovation/\#35cd8e81391b

5. C. Millar, M. Lockett, T. Ladd, Technological Forecasting and Social Change 129, 254-260 (2018).

6. C. Matt, T. Hess, A. Benlian. Business \& Information Systems Engineering 57(5), 339-343. (2015).

7. S. A. Chunikhin, E. A. Kuzmin, L. V. Pushkareva, Entrepreneurship and Sustainability Issues 6(4), 1663-1679 (2019). doi:10.9770/jesi.2019.6.4(8)

8. S. Vorobyov, L. Perlovsky, V. Yadykin. IOP Conference Series: Materials Science and Engineering 497, 012038, (2019).

9. O. Rasskazova, O. Kalinina, E. Zotova. MATEC Web of Conf. 170, 01058 (2018). 
10. O. Kalinina, L. Alekseeva, D. Varlamova, S. Barykin, I. Kapustina. E3S Web of Conferences 110, 02103 (2019).

11. V. Vilken, O. Kalinina, S. Barykin, E. Zotova. IOP Conference Series: Materials Science and Engineering (2019) DOI: 10.1088/1757-899X/497/1/012037

12. A. V. Dyubanov. On Digital Economy Development in the Novosibirsk Region. Materials of the Ministry of Economic Development of the Novosibirsk Region http://econom.nso.ru/sites/econom.nso.ru/wodby_files/files/news/2018/04/1_dyub anov.pdf

13. N. D. Bublik, I. I. Lukina, D. V. Chuvilin, T. A. Shafikov, R. F. Yunusova, Regional Economy and Management 1 (53), 34-41 (2018).

14. T. V. Ershova, Yu. E. Khokhlov. Digital Economy: Can You build It In a Region. Materials from the 10th Annual Congress of Small and Medium Businesses. (2018): https://digital.msu.ru/wp-content/uploads/2018-06-

05_Ershova_T.V._Hohlov_Yu.E.pdf

15. T. V. Ershova, Yu. E. Khokhlov, S. B. Shaposhnik, Collection of articles of teachers at the 9th International Scientific and Practical Conference "Modern Economy: Concepts and Models of Innovative Development". Moscow, 11-25 (2018).

16. V. V. Ivanov, G. G. Malinetsky. Digital Economy: Myths, Reality, Possibilities (Russian Academy of Sciences, 2017).

17. N. S. Revenko. Digital Economy of the USA in the Era of Information Globalization: Current Trends. USA and Canada: Economy, Politics, Culture. 8(572). 78-100. (2017).

18. A. Prokhorov, L. Konik. Digital Transformation: Analysis, Trends, World Experience (2018) https://ridero.ru/books/cifrovaya_transformaciya

19. Pinzaru F 2015 Managing in the Digital Economy: an introductive discussion Pannon Management Review: http://pmr.uni-pannon.hu/articles/4_2_pinzaru.pdf

20. E. N. Veduta Digital Aconomy as a Globalization Tool. (2018) http://iabrics.org/page1449476.html 